\title{
Effects of gibberellic acids on time of maturity and on yield and quality of cauliflower
}

\author{
R. BOOIJ* \\ Centre for Agrobiological Research, P.O. Box 14, NL 6700 AA Wageningen, Netherlands
}

Received 23 January 1990; accepted 27 April 1990

\begin{abstract}
The effect of an application of gibberellic acids $\left(\mathrm{GA}_{4+7}\right)$ on cauliflower was studied in a number of crops of the cultivars Delira and Elgon, grown in spring and summer of the years 1984, 1985 and 1986. Crops varied in timing of the end of the juvenile phase and of curd initation and differed in final number of leaves and length of the growing period. In most crops the period between transplanting and harvest was shortened, when $\mathrm{GA}_{4+7}$ was applied twice after the end of juvenility at a concentration of $80 \mathrm{mg} \mathrm{l}^{-1}$. The shortening of the growing period varied from crop to crop and increased when the difference between the number of leaves initiated at the time of application and the final number of leaves of the untreated crop increased. $\mathrm{GA}_{4+7}$ reduced the final number of leaves. Quality of the curds was hardly affected in most crops, but when crops were treated which displayed bracting, the bracting incidence was reduced. In crops of cv. Delira with a low final number of leaves, size and quality of the curds was reduced. The results are discussed in relation to the harvest planning of cauliflower.
\end{abstract}

Keywords: Brassica oleracea L. var. botrytis, cauliflower, gibberellin, harvest planning, flower initiation, yield, quality

\section{Introduction}

The cauliflower supply can fluctuate tremendously on farms, where cauliflowers are grown continuously during the season, despite of the use of transplanting schedules, which are based on earlier experience (Booij, unpublished; Hartmann \& Wuchner, 1965; Salter et al., 1972). The variation is mainly due to an unpredictable variation in length of the growing period of a crop and, to a lesser extent, to a variation in length of the period during which individual plants within a crop mature (Booij, unpublished).

The interval of time between transplanting and maturity (harvest) is mainly determined in a crop by the time of curd initiation (Booij, 1987; Grevsen, 1990). The time interval between maturation of the first and the last curds within a crop (harvest

* The experiments were carried out when the author was employed at the Research Station for Arable Farming and Production of Field Vegetables (PAGV) in Lelystad, the Netherlands. 
period) is affected mostly by the length of the period in which curds are initiated within the crop (Salter, 1969; Booij, 1990a).

Induction of the curd can only be achieved after a certain minimum number of leaves has been initiated (Hand \& Atherton, 1987). This minimum number of leaves characterizes the end of the juvenile phase. Time of curd initiation is influenced by temperature during induction; higher temperatures retard curd induction and temperatures above a certain limit can even prevent curd induction (Booij, 1987; Wiebe, 1972). The final number of leaves is also influenced by temperature: this number of leaves increases at increasing temperatures (Atherton et al., 1987; Booij, 1987).

The variation in time on which the phase changes, like end of juvenility and curd initiation, occur from crop to crop and within a crop from plant to plant, affects largely the variation in time of maturity. Regarding the phase transitions, temperature plays a predominant role.

An option to obtain a more even cauliflower supply during the season is a reduction of the variation in length of the growing period by reducing the variation in time of curd initiation, so that the cauliflower supply reflects more closely the transplanting schedule. Booij (1989) showed that curd induction could be affected by $\mathrm{GA}_{4+7}$ applications, if applied after the end of the juvenile phase. Especially when curd induction was delayed, due to high temperatures, a $\mathrm{GA}_{4+7}$ application advanced the time of curd maturity.

During the season crops vary in timing of several developmental transitions, like end of juvenility, curd induction and maturity.

The aim of these experiments is to relate the effect of $\mathrm{GA}_{4+7}$ on time of curd maturity, curd size and curd quality of a crop to developmental characteristics of the crop.

\section{Materials and methods}

Trials were carried out at the Research Station for Arable Farming and Production of Field Vegetables (PAGV) in Lelystad on a fertile marine clay soil in 1984, 1985 and 1986. Plants of cv. Delira (Rijk Zwaan, De Lier, NL) and cv. Elgon (Royal Sluis, Enkhuizen, NL), were raised in frames in 1984 and in an unheated glasshouse in 1985 and 1986; bare rooted transplants were planted by hand on several dates (Table 1) in a square arrangement at a density of 2.5 plants $\mathrm{m}^{-2}, 5$ to 6 weeks after sowing. The crops were treated as in commercial practice.

Samples (10-12 plants) were taken from the control plots at regular intervals starting three weeks after transplanting, until all plants in a sample had initiated a curd. By dissecting the plants, the number of leaves initiated and the developmental stage of the apex (vegetative or generative) were determined by using a binocular microscope. The apex was considered to have reached the generative phase (curd initiation) as soon as the first secondary primordia became visible (Margara \& David, 1978). The mean final number of leaves, i.e. the number of leaves initiated below the first leaf with a secondary primordium in its axil, of a crop was determined when all the plants in a sample had initiated secondary primordia.

$\mathrm{GA}_{4+7}$ (from Berelex GA 4/7 (ICI); $9 \mathrm{~g} \mathrm{l}^{-1} \mathrm{GA}_{4+7}$ ) was diluted to $80 \mathrm{mg} \mathrm{1}^{-1}$, 
and $0.25 \mathrm{ml} \mathrm{l}^{-1}$ wetting agent (Cytowet, BASF) was added. Each plant was treated separately with a propane-driven sprayer at a constant overpressure of $0.2 \mathrm{MPa}$, at a dose of $15-18 \mathrm{ml}$ of the solution. $\mathrm{GA}_{4+7}$ was applied twice to the same plant, with the second application 4 days after the first. At harvest of the 1984 trial, plants were individually assessed three times a week and were cut just before the curd would become loose (maturity) and were judged by size and quality. In 1985 and 1986 curds were not cut, but twice a week each curd was scored for quality and size. The curd was considered to be harvestable on the date of the highest score for quality (class I: no defects; class II: minor defects; class III: unmarketable) and size (size 6: $17-20 \mathrm{~cm}$; size 8: $14-17 \mathrm{~cm}$; size 10: $11-14 \mathrm{~cm}$ diameter). Bracting, riceyness, looseness and malformations were regarded as quality defects.

For each crop a cumulative frequency distribution of the number of harvested curds was made and the time on which $10 \%(\mathrm{H} 10), 50 \%(\mathrm{H} 50)$ or $90 \%$ (H90) of the curds had been harvested was estimated. The interval between the time on which $10 \%$ and $90 \%$ of the curds had been harvested is regarded as the harvest period (HP).

Regression analysis and analysis of variance (ANOVA) were carried out with the statistical program package GENSTAT (Lane et al., 1987).

Trial 1 (1984). From 240 plants, transplanted on each date (Table 1), one third was treated and two thirds were left untreated. The first of two $\mathrm{GA}_{4+7}$ applications was given at about 21 days after transplanting. Treatments were unreplicated.

Trial 2 (1985). From each plot (100 plants), half was treated and half was left untreated. Cv. Delira plants were treated for the first time when they had initiated about 19 leaves and cv. Elgon plants when they had initiated about 26 leaves.

Trial 3 (1986). With $\mathrm{cv}$. Delira the effect of time of the $\mathrm{GA}_{4+7}$ application was studied and with $\mathrm{cv}$. Elgon the effect of application time and $\mathrm{GA}_{4+7}$ concentration was examined. The first of the two $\mathrm{GA}_{4+7}$ applications was given at the time when about 19 leaves had been initiated (T1), 2 (T2) or 4 (T3) days later, but at the earliest 20 days after transplanting. The $\mathrm{GA}_{4+7}$ concentrations applied to $\mathrm{cv}$. Elgon were 80,120 of $160 \mathrm{mg} \mathrm{l}^{-1}$. Each treatment was replicated three times and for the final harvest each plot consisted of 42 plants in case of cv. Delira and 25 plants in case of cv. Elgon. After all untreated plants of cv. Delira had initiated a curd, a sample (15 plants) was taken from the treated plots and the final number of leaves was counted.

\section{Results}

\section{Time of maturity}

Characteristics of the untreated plots are presented in Table 1. The crops varied in time on which the 19th leaf was initiated, in time on which $50 \%$ of the plants within a crop had initiated a curd and in the mean final number of leaves. 


\section{R. BOOIJ}

Table 1. Transplanting date, time (days after transplanting) on which mean number of leaves equaled 19 , time on which $50 \%$ of the plants had initiated a curd, mean final number of leaves, time (days after transplanting) of first $\mathrm{GA}_{4+7}$ application and number of leaves initiated at that time of all crops studied. (Experiment 1: 1984; Experiment 2: 1985; Experiment 3: 1986).

\begin{tabular}{|c|c|c|c|c|c|}
\hline \multirow{2}{*}{$\begin{array}{l}\text { Crop } \\
\text { number }\end{array}$} & \multirow{2}{*}{$\begin{array}{l}\text { Transplanting } \\
\text { date }\end{array}$} & \multirow{2}{*}{$\begin{array}{l}\text { Initiation } \\
\text { leaf } 19 \\
\text { (d) }\end{array}$} & \multirow{2}{*}{$\begin{array}{l}\text { Curd } \\
\text { initiation } \\
\text { (d) }\end{array}$} & \multirow{2}{*}{$\begin{array}{l}\text { Mean } \\
\text { final number } \\
\text { of leaves }\end{array}$} & First application \\
\hline & & & & & $\begin{array}{ll}\text { time (d) number of } \\
\text { leaves }\end{array}$ \\
\hline
\end{tabular}

Delira

\begin{tabular}{rrrrrrr}
1 & $84-05-15$ & 25 & 32 & 27.5 & 21 & 16.9 \\
2 & $84-05-23$ & 25 & 35 & 27.4 & 21 & 15.8 \\
3 & $84-05-29$ & 28 & 32 & 24.8 & 21 & 15.0 \\
4 & $84-06-05$ & 27 & 32 & 23.4 & 21 & 14.7 \\
5 & $84-06-19$ & 23 & 31 & 27.3 & 24 & 20.9 \\
6 & $84-07-10$ & 28 & 38 & 33.3 & 21 & 14.4 \\
7 & $85-05-22$ & 28 & 35 & 23.3 & 26 & 17.4 \\
8 & $85-05-29$ & 30 & 37 & 28.0 & 27 & 17.2 \\
9 & $85-06-05$ & 29 & 40 & 33.0 & 29 & 18.2 \\
10 & $85-06-13$ & 26 & 39 & 31.5 & 25 & 18.0 \\
11 & $85-06-19$ & 27 & 36 & 31.1 & 27 & 19.2 \\
12 & $86-05-21$ & 25 & 37 & 36.0 & 26 & 20.1 \\
13 & $86-05-27$ & 26 & 42 & 36.8 & 24 & 18.0 \\
14 & $86-06-03$ & 21 & 38 & 33.9 & 22 & 19.5 \\
15 & $86-06-10$ & 21 & 34 & 33.1 & 21 & 19.0 \\
16 & $86-06-18$ & 20 & 28 & 30.4 & 20 & 19.1 \\
& & & & & & \\
Elgon & & & & & & \\
1 & & & 32 & 31.2 & 24 & 27.1 \\
2 & $84-06-19$ & & 33 & 31.8 & 20 & 15.3 \\
3 & $84-06-26$ & 25 & 27 & 34.1 & 21 & 22.1 \\
4 & $84-07-03$ & 18 & 41 & 39.8 & 21 & 17.1 \\
5 & $84-07-10$ & 25 & 50 & 40.8 & 36 & 25.2 \\
6 & $85-06-05$ & 28 & 36 & 37.8 & 28 & 29.1 \\
7 & $85-06-13$ & 22 & 34 & 36.3 & 28 & 26.7 \\
8 & $85-06-19$ & 23 & 35 & 33.2 & 27 & 26.1 \\
9 & $85-07-04$ & 21 & 41 & 40.9 & 22 & 20.5 \\
10 & $86-06-03$ & 21 & 34 & 39.2 & 21 & 22.4 \\
11 & $86-06-10$ & 16 & 30 & 37.7 & 20 & 23.3 \\
12 & $86-06-18$ & 16 & 29 & 36.7 & 21 & 23.6 \\
13 & $86-06-24$ & 16 & 15 & & 20 & 23.4 \\
\hline
\end{tabular}

The effect of a $\mathrm{GA}_{4+7}$ treatment on the maturity time (number of days after transplanting) of a crop was expressed as the difference in time of maturity between the untreated and the corresponding treated plot. Positive values mean an advancement of maturity and negative values a delay. In most crops $\mathrm{H} 10$ and $\mathrm{H} 50$ was advanced by an application of $\mathrm{GA}_{4+7}$, however, in some crops $\mathrm{H} 10$ was delayed (Fig. 1). As not all crops were treated exactly at the same developmental stage (i.e. the number of leaves initiated) and there were also differences between crops in the 

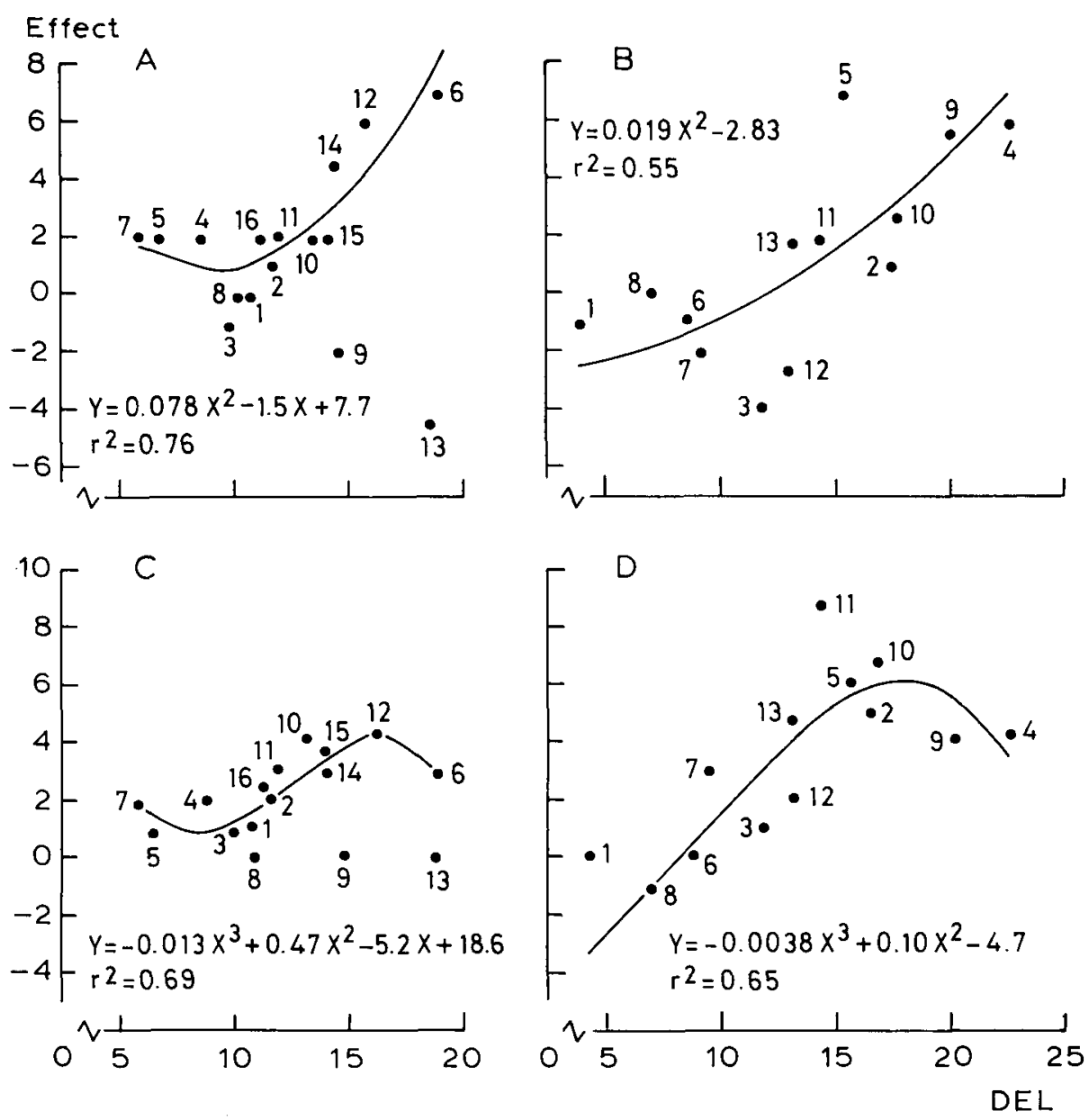

Fig. 1. Relationship between the difference (DEL) in the number of leaves at the time $\mathrm{GA}_{4+7}$ was applied and the final number of leaves of control plants and the effect (difference between untreated and treated in days) of $\mathrm{GA}_{4+7}$ on the time that $10 \%(\mathrm{~A}, \mathrm{~B})$ or $50 \%(\mathrm{C}, \mathrm{D})$ of the curds had been harvested. Cv. Delira $(A, C)$ and $c v$. Elgon $(B, D)$. Numbers attached to the points in the figure are crop numbers (Table 1). Best fitting significant regression equations are given.

mean final number of leaves (Table 1), the effect of a $\mathrm{GA}_{4+7}$ treatment was related to the difference in these numbers of leaves. From Trial 3 (1986) only the results of T1 were included. In general, the advancement of $\mathrm{H} 10$ and $\mathrm{H} 50$ increased at increasing difference in the number of leaves. The effect on H50 diminished again when the difference was higher than 15 leaves. Two crops of cv. Delira ( 9 and 13) deviated clearly from the relation; no 9 was severely damaged by pigeons and from no 13 a number of plants was clearly infected with Rhizoctonia solani. Therefore these two crops were omitted from the regression analysis. The relationship between the difference in number of leaves and the effect of $\mathrm{GA}_{4+7}$ on time of maturity 


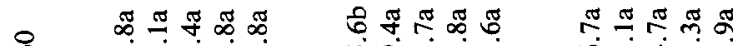

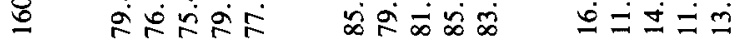

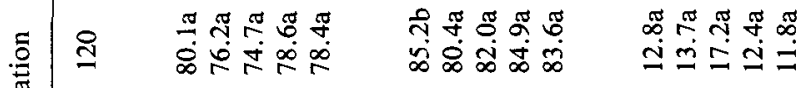

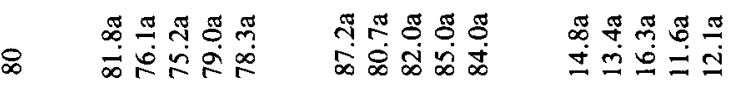

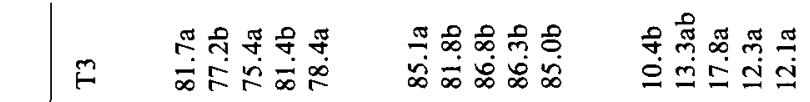

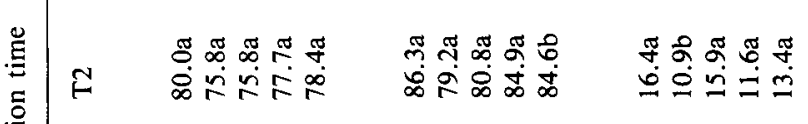

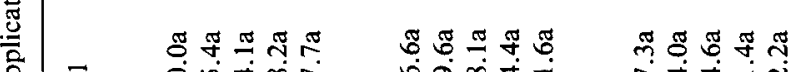

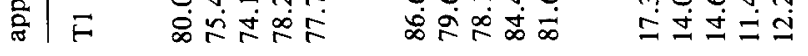

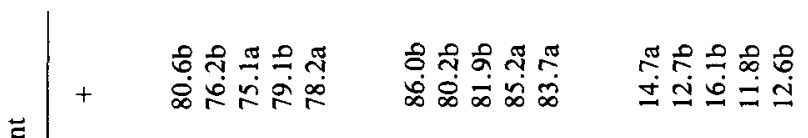

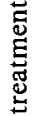

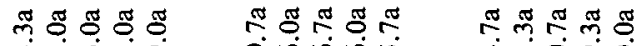

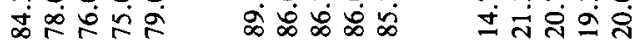

它䓪

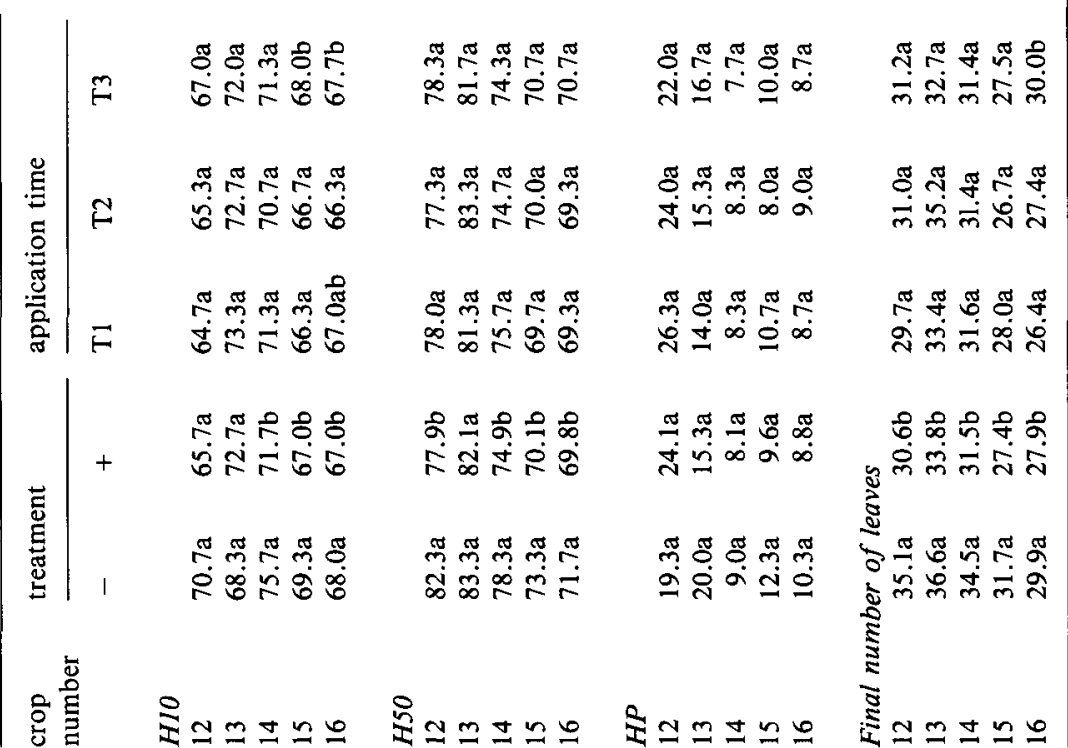


could be described by a second order polynomial for the effect on $\mathrm{H} 10$ and by a third order polynomial for the effect on $\mathrm{H} 50$. Only significant $(P<0.05)$ terms were included.

The experiments which were carried out in 1986 could be analysed on significance of the effects and the results are presented in Table 2. In all crops of 1986 H50 was advanced by a $\mathrm{GA}_{4+7}$ treatment and in 4 out of 5 crops this difference was significant $(P<0.05)$ for both cultivars. The effect on $\mathrm{H} 10$ was only significant in 3 out of 5 crops (both cultivars). There was no significant effect of time of application on $\mathrm{H} 50$ of cv. Delira and only in two crops there was a significant effect on H10. $\mathrm{Cv}$. Elgon showed a different picture, there was a significant effect of time of application on $\mathrm{H} 50$ in 4 out of 5 crops and in 2 out of 5 crops this was true for H10. Time of maturity was less advanced, when $\mathrm{GA}_{4+}$, was applied later (Table 2). $\mathrm{GA}_{4+7}$ concentration had only a significant effect in 1 crop of cv. Elgon and in none of the crops there was a significant interaction between application time and concentration.

The estimates for the coefficients of the polynomials for respectively $\mathrm{H} 10$ and H50 (Fig. 1) indicate an effect of $\mathrm{GA}_{4+7}$ application on length of the harvest period. $\mathrm{A} \mathrm{GA}_{4+7}$ application reduced $\mathrm{HP}$ in many crops (Fig. 2), in particular of cv. Elgon. From the experiment in 1986, it can be concluded that a $\mathrm{GA}_{4+7}$ treatment reduced HP significantly $(P<0.05)$ in 4 out of 5 crops of $\mathrm{cv}$. Elgon and in $2 \mathrm{crops}$ a significant effect of time of application was found (Table 2). $\mathrm{GA}_{4+7}$ concentration did not have a significant effect on HP. Although a $\mathrm{GA}_{4+7}$ application
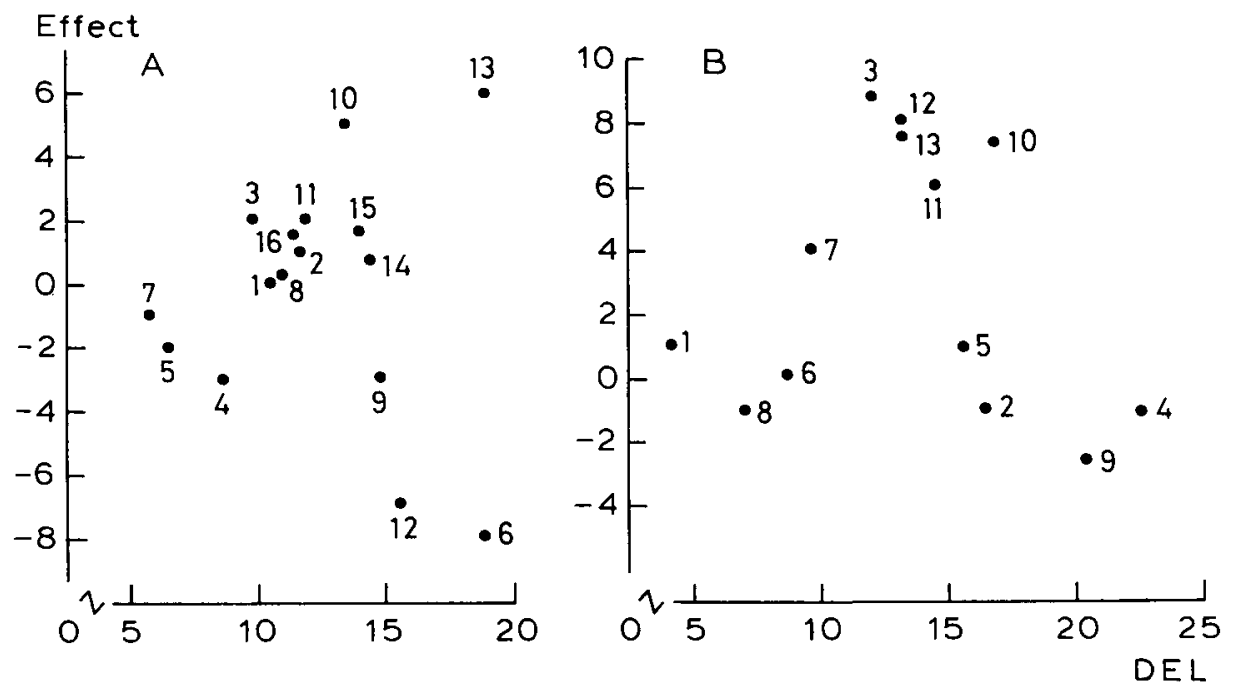

Fig. 2. Relationship between the difference (DEL) in the number of leaves at the time $\mathrm{GA}_{4+7}$ was applied and the final number of leaves of control plants and the effect (difference between untreated and treated in days) of $\mathrm{GA}_{4+7}$ on length of the harvest period of cv. Delira (A) and cv. Elgon (B). Numbers attached to the points in the figure are crop numbers (Table 1). 


\section{R. BOOIJ}

reduced HP in all crops of cv. Delira in 1986, there was no significant effect in any crop.

\section{Final number of leaves}

The final number of leaves of treated plants of $\mathrm{cv}$. Delira was only determined in 1986. A $\mathrm{GA}_{4+7}$ application reduced the final number of leaves significantly $(P<0.05)$ in all crops (Table 2 ). Only in 1 out of 5 crops the time of $\mathrm{GA}_{4+7}$ application had a significant effect on the final number of leaves.

\section{Size grade and quality}

Harvested curds were graded according to diameter and curds harvested with the largest diameter were of Grade 6. The proportion of curds of this size class varied for the different crops and its percentage was plotted against the mean final number of leaves of the corresponding control plants. In general the proportion of Grade 6 increased at increasing final number of leaves, with the exception of a number of crops grown in 1984 which had a very low percentage of Grade $6(<10 \%)$ (Fig. 3 ). The proportion of curds of Grade 6 was hardly influenced by a $\mathrm{GA}_{4+7}$ treatment when $\mathrm{GA}_{4+7}$ was applied to crops of cv. Elgon. $\mathrm{GA}_{4+7}$ reduced curd size when applied to cv. Delira crops with a lower final number of leaves (Fig. 3).

Curd quality (expressed as the proportion of curds of quality Grade II) was in particular affected negatively, if $\mathrm{GA}_{4+7}$ was applied to crops of cv. Delira with a low final number of leaves. Quality in the crops with a low final number of leaves was mainly reduced by green tips of a few low order bracts growing through the surface of the curd. A $\mathrm{GA}_{4+7}$ application improved curd quality of cv. Elgon in many crops, as it suppressed bracting.

\section{Discussion}

Variation in length of the growing period from crop-to-crop is mainly the result of a variation in the time of curd initiation (Booij, 1987; Grevsen, 1990). Time of curd initiation depends on the end of the juvenile phase (i.e. when a certain number of leaves has been initiated (Hand \& Atherton, 1987)) and the temperature during the subsequent induction period (Booij, 1990a). With increasing temperature length of the induction period increases, curd initiation is retarded and the final number of leaves increases. As the final number of leaves is fixed at the time of curd initiation, the mean final number of leaves of a crop can be regarded as a measure for the temperature conditions during curd induction and for the delay of curd initiation of the considered crop. As $\mathrm{GA}_{4+7}$ can accelerate curd induction (Booij, 1989), the advancement of maturity after a timely $\mathrm{GA}_{4+7}$ application is supposed to be more on crops which should have initiated a high final number of leaves without a $\mathrm{GA}_{4+7}$ application. The difference between the final number of leaves of untreated plants and the number of leaves initiated at the time of application is a measure for the advancement towards curd initiation of the crop at that time. In the present experi- 

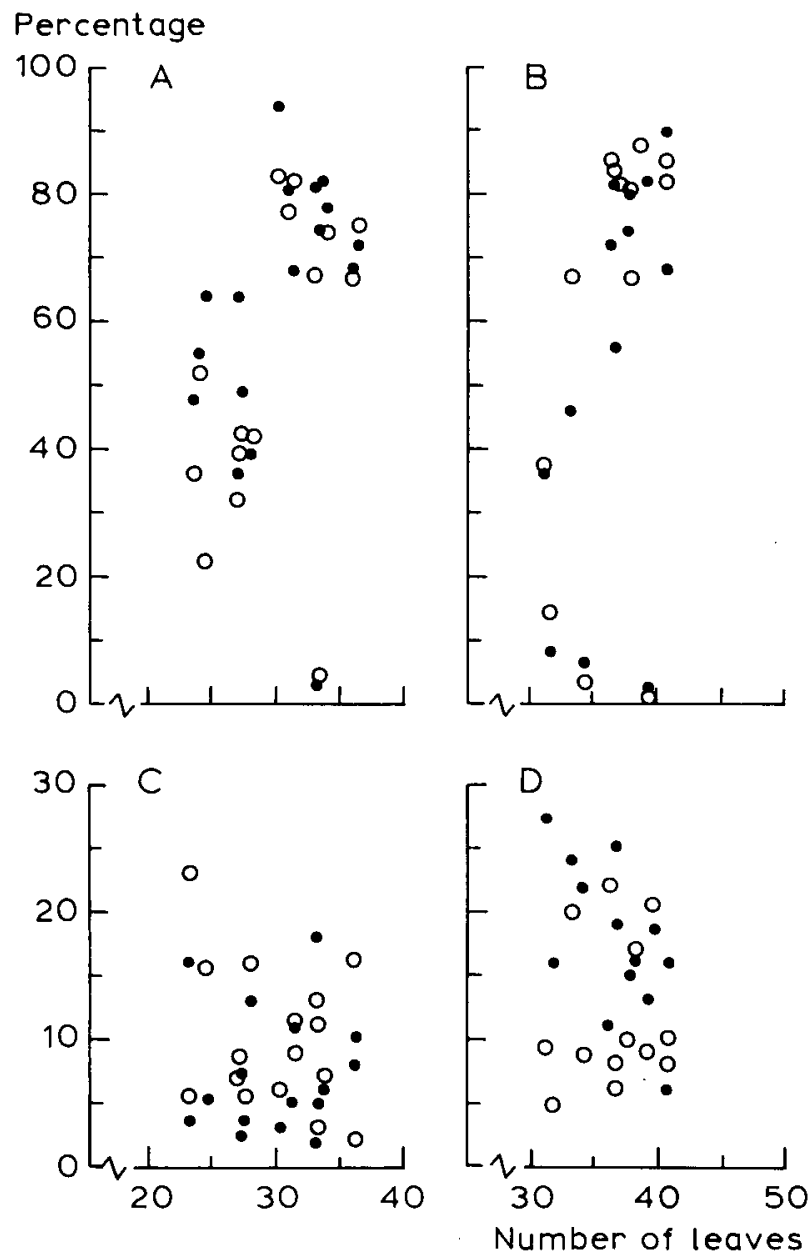

Fig. 3. Relationship between the final number of leaves of the control plants and curd size (percentage of curds Grade 6) (A,B) and curd quality (proportion of curds in Class II) $(C, D)$ of cv. Delira $(A, C)$ and cv. Elgon $(B, D)$ for untreated $(\bullet)$ and treated $(0)$ plants.

ments $\mathrm{GA}_{4+7}$ affected the number of days between transplanting and maturity more, when the advancement towards curd initiation was less (difference in number of leaves high) at the time of application (Fig. 1). In this context the end of juvenility needs to be regarded, as an application of $\mathrm{GA}_{4+7}$ before the end of juvenility is expected to be less or not at all effective. The end of juvenility was determined to be for cv. Delira at about 18 leaves initiated and for cv. Elgon at about 19 leaves initiated (Booij, 1990a). From Table 1 can be concluded that the first $\mathrm{GA}_{4+7}$ application was in most crops after or just before the end of juvenility. At higher differences in the number of leaves (Fig. 1C, D) the effect of $\mathrm{GA}_{4+7}$ on length of the growing period was less again, so probably $\mathrm{GA}_{4+7}$ could not substitute completely the tem- 
perature requirement for induction, especially when temperatures were highest. Despite the significant correlation between the difference in the number of leaves and the effect of $\mathrm{GA}_{4+7}$ on length of the growing period, there was still a considerable residual variation (Fig. 1).

Although the length of the growing period could be significantly reduced, there was still a considerable variation in length of the growing period of the separate crops (Table 2) and in the final number of leaves in treated crops (Table 2). Especially the last indicates that a constant length of the curd induction period could not be obtained by a $\mathrm{GA}_{4+7}$ application.

However, a constant length of the growing period could not be achieved, because crops varied in time on which juvenility ends (Table 1) and a $\mathrm{GA}_{4+7}$ application did not result in a constant length of the induction period (Table 2). So it does not seem sensible to apply $\mathrm{GA}_{4+7}$ to all crops as a kind of common practice. As the time of maturity is related to the time of curd initiation, the harvest pattern during the season can be predicted from the pattern of curd initiation. A decision about applying $\mathrm{GA}_{4+7}$ to a certain crop can be based on the pattern of curd initiation until that moment and the expected number of curds to be initiated during the next days, using information about the developmental stage and the temperature during the preceding period and the expected temperature during the next period.

The relation between curd size and final number of leaves (Fig. 3) is in agreement with the results of Wurr et al. (1988). There was only an effect of $\mathrm{GA}_{4+7}$ on curd size in crops of cv. Delira that had initiated curds at a low number of leaves (Fig. $3 \mathrm{~A}$ ); the reduction in size is likely due to a further reduction in final number of leaves by $\mathrm{GA}_{4+7}$. A reduction in final number of leaves, as a result of an earlier curd initiation, will have a larger impact on curd size at a low final leaf number, when the risk of buttoning is more obvious.

Quality was reduced, when $\mathrm{GA}_{4+7}$ was applied to crops of cv. Delira with a low final number of leaves (Fig. 3), mainly because of the appearance of a few large green bracts at the bottom of the curd. This is probably not caused by a stimulation of bract growth, but due to the reduction of the final number of leaves. Rate of increase in length of a leaf primordium decreases at increasing leaf number (Booij \& Struik, 1990), therefore the relation between the bract and the secondary primordium in its axil will depend on the total number of leaves initiated at the time the first secondary primordia are initiated. When the final number of leaves is reduced, due to $\mathrm{GA}_{4+7}$, on crops with a low final number of leaves, the appearance of large bracts at the bottom of the curd is more likely. It seems that $\mathrm{GA}_{4+7}$ can reduce bracting as it has occurred in a number of crops of cv. Elgon (Fig. 3). Cv. Elgon is susceptible to bracting which dan be induced by high temperature (Fujime, 1983) or ethephon (Booij, 1990b). It should be interesting to study these interrelations and the prospects of using $\mathrm{GA}_{4+7}$ as a tool in preventing bracting more in depth.

\section{Acknowledgements}

The author wishes to thank Prof. H. Challa, Prof. P. C. Struik, Dr S. C. van de Geijn and Ir A. P. Everaarts for critical comments on the manuscript. 


\section{References}

Atherton, J. G., D. J. Hand \& C. A. Williams, 1987. Curd initiation in the cauliflower (Brassica oleracea var. botrytis L.). In: J. G. Atherton (Ed.), Manipulation of flowering, p. 133-145. Butterworths, London.

Booij, R., 1987. Environmental factors in curd initiation and curd growth of cauliflower in the field. Netherlands Journal of Agricultural Science 33:435-445.

Booij, R., 1989. Effect of growth regulators on curd diameter of cauliflower. Scientia Horticulturae 38:23-32.

Booij, R., 1990a. Cauliflower curd initiation and maturity: variability within a crop. Journal of Horticultural Science 65:167-175.

Booij, R., 1990b. Genotypic differences for induction of bracting in cauliflower with 2chloroethylphosphonic acid (ethephon). Euphytica 50: 27-33.

Booij, R. \& P. C. Struik, 1990. Effects of temperature on leaf and curd initiation in relation to juvenility of cauliflower. Scientia Horticulturae (in press).

Fujime, Y., 1983. Studies on thermal conditions of curd formation and development in cauliflower and broccoli, with special reference to abnormal curd development. Memoirs of Faculty of Agriculture Kagawa University, No 40, Miki-tyô, Kagawa-ken, 123 pp.

Grevsen, K., 1990. Prediction of harvest in cauliflower based on meteorological observations. Acta Horticulturae 267: 313-322.

Hand, D. J. \& J. G. Atherton, 1987. Curd initiation in the cauliflower. I. Juvenility. Journal of Experimental Botany 38:2050-2058.

Hartmann, H. D. \& A. Wuchner, 1965. Freilandblumenkohl als Terminkultur. Gemüse 1:41-43.

Lane, P., N. Galwey \& N. Alvey, 1987. Genstat 5. An introduction. Clarendon Press, Oxford, 163 pp.

Margara, J. \& C. David, 1978. Les étapes morphologiques du développement du méristème de Choufleur, Brassica oleracea L. var. botrytis. Comptes Rendus des Séances de l'Académie de Science, Série D 287:1369-1372.

Salter, P. J., 1969. Studies on crop maturity in cauliflower: I Relationship between the times of curd initiation and curd maturity of plants within a cauliflower crop. Journal of Horticultural Science 44:129-140.

Salter, P. J., R. J. Ward \& J. D. Whitwell, 1972. Studies on methods of obtaining continuity of production of summer and autumn cauliflowers. I. Kirton, 1963-1969. Experimental Horticulture 23:1-22.

Wiebe, H. J., 1972, Wirkung von Temperatur und Licht auf Wachstum und Entwicklung von Blumenkohl. II. Optimale Vernalisationstemperatur und Vernalisationsdauer. Gartenbauwissenschaft 37:293-303.

Wurr, D. C. E., E. D. Elphinstone \& J.R. Fellows, 1988. The effect of plant raising and cultural factors on the curd initiation and maturity characteristics of summer/autumn cauliflower crops. Journal of Agricultural Science (Cambridge) 111:427-434. 